Division of Geriatrics and Palliative Care in the Department of Medicine New York University Grossman School of Medicine, New York, NY, USA

2 Department of Population Health, New York University Grossman School of Medicine, New York, NY

3 VA New York Harbor Healthcare System, New York, NY

4 Audiology Program, Graduate Center, City University of New York, NY

5 Robert F Wagner Graduate School of Public Service, New York University, New York, NY

Correspondence to: I Blustein jan.blustein@wagner.nyu.edu Cite this as: BMJ 2020;370:m2683 http://dx.doi.org/10.1136/bmj.m2683 Published: 09 July 2020

\section{Face masks can be devastating for people with hearing loss}

\author{
Innovation is urgently needed to ensure clear communication in medical settings \\ Joshua Chodosh, 1, 2,3 Barbara E Weinstein, ${ }^{1,4}$ Jan Blustein ${ }^{2,5}$
}

The covid-19 pandemic has literally changed the face of medical care: clinicians, nurses, other staff, and patients are all wearing masks. We are trying to communicate while keeping the required distance apart. With masks covering the faces around us, we are unable to access the facial expressions and lip movements that are so vital to daily communication.

Masking is challenging for everyone, but it is especially difficult for people with hearing loss. Here we focus on how masks undermine speech communication for patients with hearing loss in medical care settings. Masks also create enormous challenges for members of the Deaf community who use sign language, clinicians with hearing loss, and other populations.

Communication between patient and clinician is at the heart of medical care. Even before masks became ubiquitous, people with hearing loss struggled to communicate in healthcare settings, ${ }^{1-3}$ and poor communication was the likely cause of their documented worse health outcomes. ${ }^{45}$ Spoken communication has always been especially challenging in emergency departments and hospital wards owing to high levels of noise and poor environmental engineering. ${ }^{6}$ Those challenges remain, but masks bring new barriers: in addition to blocking lip movements and facial expressions (which are so important when hearing is marginal), masks muffle the high frequency portions of sound that are essential to speech. ${ }^{7}$

How can we preserve communication with patients with hearing loss in this new masked world? The first step is awareness-we can be mindful that many patients will struggle to understand speech delivered through a mask. We should be especially alert to the possibility of hearing loss with older patients, as over two thirds of people over 70 have clinically significant loss. ${ }^{8}$ Second, basic steps can often improve communication. Face the patient, get their attention before speaking, speak reasonably slowly, raise the volume of our voices slightly, and always check for understanding. Non-response or an inappropriate response might be a sign of hearing difficulty.

Low tech aids such as white boards or yellow pads can be useful. Smartphones and tablets offer real time speech-to-text transcription-many apps now run with remarkable speed and accuracy, and some tech savvy patients are using them. Healthcare facilities might be required under law to provide speech-to-text transcription for patients needing it. ${ }^{910}$ For some patients, a handy facilitator of spoken communication is the personal amplifier, which consists of a microphone and an amplifier that feeds the conversational partner's voice directly into the wearer's ears through wired headphones or earbuds.
Personal amplifiers do not require customisation by a professional; simple volume and tuning controls allow for easy use, out of the box. They can be stocked with hospital supplies and cost around \$60-\$200 (£50-€160; €50-€180).

Face masks with clear windows could allow access to facial expressions and lip movements, but there are few manufacturers and supplies are low. ${ }^{11}$ Moreover, regulatory barriers to the use of clear masks remain in medical settings. ${ }^{12}$ Clearing these barriers is an urgent priority. Around the world, people with hearing loss, including those in the Deaf community, are fashioning their own clear masks. ${ }^{13}$ This will be an area for product innovation and activism in the future.

Virtual consultations are a potential solution for some patients. But many people with hearing loss, especially those with more severe loss, need captioning to understand speech delivered through online platforms. High quality real time speech-to-text captioning is offered for free on some platforms (such as Google Meet and Microsoft Teams), but other platforms (such as Zoom and FaceTime) lag behind. ${ }^{14}$ Free access to online captions is another priority for innovation and activism going forward. ${ }^{15}$

Clinicians and other staff with hearing loss face similar challenges to those enumerated here. Patients and healthcare workers who are members of the Deaf community and use sign language face the greatest obstacles with masking, since facial expressions and lip movements are fundamental components of sign language. In healthcare settings, remote (video) sign language interpretation services must be provided, or patients and interpreters should be allowed to remove masks. These issues should be resolved urgently as good healthcare outcomes depend on clear channels of communication, particularly during a lethal pandemic.

Face masks are likely to be a feature of patient care for a long time to come. In early June the World Health Organization noted that mask use in medical care settings introduces potential harms and risks that "should be carefully taken into account" when caring for members of several populations, including the deaf and hard of hearing community." ${ }^{16}$ Masking in healthcare will be an area of activism and practice innovation in the months to come. Adopting simple strategies can help maximise communication while innovation ramps up.

Competing interests: We have read and understood BMJ policy on competing interests and have no relevant conflicts to declare.

Provenance and peer review: Not commissioned, peer reviewed. 
We thank Kate Radcliffe, Shari Eberts, Richard Einhorn, Zina Jawadi, and Ayla Ozmen for astute comments on previous drafts.

1 Mick P, Foley DM, Lin FR. Hearing loss is associated with poorer ratings of patient-physician communication and healthcare quality. J Am Geriatr Soc 2014;62:2207-9.

doi: 10.1111/jgs.13113 pmid: 25413192

2 Cudmore V, Henn P, O'Tuathaigh CMP, Smith S. Age-related hearing loss and communication breakdown in the clinical setting. JAMA Otolaryngol Head Neck Surg 2017;143:1054-5. doi: 10.1001/jamaoto.2017.1248 pmid: 28837709

3 Shukla A, Nieman CL, Price C, Harper M, Lin FR, Reed NS. Impact of hearing loss on patient-provider communication among hospitalized patients: A systematic review. Am J Med Qual 2019;34:284-92. doi: 10.1177/1062860618798926 pmid: 30196712

4 Chang JE, Weinstein B, Chodosh J, Blustein J. Hospital readmission risk for patients with self-reported hearing loss and communication trouble. J Am Geriatr Soc 2018;66:2227-8. doi: 10.1111/jgs.15545 pmid: 30289969

5 Reed NS, Altan A, Deal JA, etal. Trends in health care costs and utilization associated with untreated hearing loss over 10 years. JAMA Otolaryngol Head Neck Surg 2019;145:27-34. doi: 10.1001/jamaoto.2018.2875 pmid: 30419131

6 Blustein J, Weinstein BE, Chodosh J. Tackling hearing loss to improve the care of older adults. BMJ 2018;360:k21. doi: 10.1136/bmj.k21 pmid: 29348197

7 Goldin A, Weinstein BE, Shiman N. How do medical masks degrade speech reception? Hearing Review. May 2020. https://www.hearingreview.com/hearing-loss/health-wellness/how-domedical-masks-degrade-speech-reception

8 Lin FR, Niparko JK, Ferrucci L. Hearing loss prevalence in the United States. Arch Intern Med 2011;171:1851-2. doi: 10.1001/archinternmed.2011.506 pmid: 22083573

9 United States Department of Justice. ADA requirements: Effective communication. https://www.ada.gov/effective-comm.htm

10 NHS England. Accessible information standard. https:/www.england.nhs.uk/ourwork/accessibleinfo/

11 Safe'N'Clear. The communicator clear window surgical mask. https://safenclear.com/product/communicator-box/

12 Action on Hearing Loss. Coronavirus position statement. Updated 9 June 2020. https://actiononhearingloss.org.uk/about-us/research-and-policy/coronavirus-policy-statement/

13 Taylor-Coleman J. Coronavirus: Call for clear face masks to be "the norm." BBC News 2020 May 26. https://www.bbc.com/news/world-52764355.

14 Eberts S. Petition update: two down: only zoom to go. https://www.change.org/p/zoom-providefree-captions-for-people-with-hearing-loss-on-video-conferencing-platforms/u/26778357

15 Eberts S. Captions are our ramps. https://livingwithhearingloss.com/2020/04/28/hearing-lossadvocacy-captions-are-our-ramps/

16 World Health Organization. Advice on the use of masks in the context of COVID-19: Interim guidance. https://www.who.int/publications/i/item/advice-on-the-use-of-masks-in-the-communityduring-home-care-and-in-healthcare-settings-in-the-context-of-the-novel-coronavirus-(2019ncov)-outbreak

This article is made freely available for use in accordance with BMJ's website terms and conditions for the duration of the covid-19 pandemic or until otherwise determined by BMJ. You may use, download and print the article for any lawful, non-commercial purpose (including text and data mining) provided that all copyright notices and trade marks are retained. 